\title{
Widespread exposure to Sarcoptes scabiei in wild European rabbits (Oryctolagus cuniculus) in Spain
}

\author{
J. Millán a,*, R. Casáis ${ }^{\mathrm{b}}$, M. Delibes-Mateos ${ }^{\mathrm{c}}$, C. $^{\mathrm{a}}$ Calvete $^{\mathrm{d}}$, C. Rouco e,f, F. Castro ${ }^{\mathrm{c}}$, V. Colomar ${ }^{\mathrm{g}}$, \\ E. Casas-Díaz ${ }^{\mathrm{a}}$, E. Ramírez ${ }^{\mathrm{c}}$, S. Moreno ${ }^{\mathrm{e}}$, J.M. Prieto ${ }^{\mathrm{b}}$, R. Villafuerte $^{\mathrm{c}}$ \\ a Servei d'Ecopatologia de Fauna Salvatge (SEFaS) (Wildlife Diseases Research Group), Departament de Medicina i Cirurgia Animals, Universitat Autònoma de \\ Barcelona, 08193 Bellaterra, Spain \\ b Servicio Regional de Investigación y Desarrollo Agroalimentario (SERIDA), Centro de Biotecnología Animal, La Olla-Deva, 33394 Gijón (Asturias), Spain \\ c Instituto de Investigación en Recursos Cinegéticos, IREC (CSIC-UCLM-JCCM), Ronda de Toledo s/n, E-13071 Ciudad Real, Spain \\ d Agrifood Research and Technology Centre of Aragon, Animal Health Department, Ctra. Montañana 930, 50059 Zaragoza, Spain \\ e Department of Applied Biology, Estación Biológica de Doñana CSIC, Avda. María Luisa s/n, 41013 Seville, Spain \\ f Landcare Research, PO Box 282, 9340 Alexandra, New Zealand \\ g Fundació Natura Parc, 07142 Santa Eugènia (Balearic Islands), Spain
}

\section{A R T I C L E I N F O}

\section{Article history:}

Received 15 February 2011

Received in revised form 12 July 2011

Accepted 25 July 2011

\section{Keywords:}

Ectoparasite

Lagomorph

Mite

Scabies

Translocation

\begin{abstract}
A B S T R A C T
Sarcoptic mange was recently described in the wild European rabbit (Oryctolagus cuniculus) in north-eastern Mediterranean Spain, the first such infection reported in this species anywhere in the world. This finding has created concern in conservationists and game managers given that an outbreak of mange after a translocation would have catastrophic consequences for naïve rabbit populations in other parts of Spain. A retrospective serosurvey using an 'in house' ELISA test based on the use of a recombinant antigen aimed at determining the rates of contact with Sarcoptes scabiei was carried out on sera from 966 rabbits collected between 1993 and 2010 in Spain. Antibodies were found in 13\% of wild rabbits in $60 \%$ of the 53 areas surveyed, as well as in 16 of the 17 Spanish provinces and islands studied. Seropositive rabbits were found amongst the oldest samples analyzed and in all studied years. Antibodies were also detected in $36 \%$ of rabbits from the protected island of Dragonera, where rabbits have probably not been released since the 1970s. On Mallorca, where 89 rabbits were inspected for both lesions and antibodies, the prevalence of lesions (5.6\%) was much lower than the seroprevalence (22.5\%), indicating that rabbits often survive infection or that ELISA detects infected rabbits before they develop visible lesions. Seroprevalence was higher in areas with medium levels of rabbit abundance, no restocking and high rainfall. The results show that mange is widespread in rabbits and that the mite is not a recent introduction. Thus, sarcoptic mange could be considered as an enzootic disease in the wild rabbit and so prophylactic measures implemented during rabbit translocations are to be encouraged to avoid local outbreaks in naïve populations.
\end{abstract}

(c) 2011 Elsevier B.V. All rights reserved.

\section{Introduction}

Sarcoptic mange is a highly contagious parasitic infection caused by a mite (Sarcoptes scabiei) that burrows into

\footnotetext{
* Corresponding author. Tel.: +34 610241785 .

E-mail address: syngamustrachea@hotmail.com (J. Millán).
}

the epidermis of animals (Pence and Ueckermann, 2002). When introduced into a naïve population, it can lead to high morbidity and mortality rates. For example, in southern Spain, a mange epizooty affected up to $81 \%$ of a wild population of Spanish ibex (Capra pyrenaica) within a few months of the first cases being detected and eventually led to $100 \%$ mortality (León-Vizcaíno et al., 1999). Sarcop- 
tic mange is also thought to have affected the abundance of other wild species (e.g., Mörner, 1992; Skerratt et al., 1998). In Spain, despite being known to affect various animal species (Fernández-Morán et al., 1997; Gortazar et al., 1998; González-Candela et al., 2004; Oleaga et al., 2008a,b), the first cases of scabies in European wild rabbits (Oryctolagus cuniculus) were only recently reported (Millán, 2010).

The wild European rabbit is native to the Iberian Peninsula and is regarded as a keystone species in Iberian Mediterranean ecosystems (Delibes-Mateos et al., 2008a) due to its vital role as prey item for at least 29 predators (Delibes and Hiraldo, 1981) and as an ecosystem engineer (Gálvez-Bravo et al., 2009). Moreover, it is one of the main small game species traditionally hunted in this region (Angulo and Villafuerte, 2003). Although rabbits were historically numerous and widespread, habitat loss and the introduction of two viral diseases, myxomatosis in the 1950s and rabbit hemorrhagic disease (RHD) in 1989, resulted in a dramatic decline in rabbit populations in the second half of the twentieth century (Villafuerte et al., 1995; Calvete et al., 2002; Delibes-Mateos et al., 2010). The translocation and/or release of wild-caught or farm-reared wild rabbits are two very common practices in rabbit management and became much more frequent in the 1990s (Delibes-Mateos et al., 2008b), apparently as a consequence of the devastating effect of RHD on most Iberian rabbit populations.

It is still open to debate whether sarcoptic mange is enzootic in the Iberian wild rabbit population or whether it was introduced with released/translocated wild rabbits after contact with domestic rabbits. Nevertheless, researchers must strive to answer this question given that naïve rabbit populations may be put at risk by the introduction of mange, which will have a serious effect on local populations. To date, cases of scabies in wild rabbits have been only reported in a number of Mediterranean regions in northern and eastern Spain, namely in the Balearic Islands, Catalonia and Valencia (Millán, 2010; Navarro-González et al., 2010; Sánchez, pers. comm.). A study based on interviews with hunters in Catalonia indicated that mange cases were more frequent in areas where rabbit releases are carried out and detected a negative trend in rabbit populations in affected areas (Navarro-González et al., 2010). This apparently supports the hypothesis that mange was introduced - at least into the areas studied in the aforementioned article. However, mange cases have also been observed in some areas of Mallorca (Balearic Islands) where no rabbits have been released recently and, moreover, where the density of rabbits is so high as to cause important damage to crops (Millán, pers. obs.). In fact, Navarro-González et al. (2010) also found that local rabbit abundances were positively related with the occurrence of mange, which would seem to suggest that the hypothesis that mange is enzootic in rabbits and that outbreaks are due to as-yet undetermined factors cannot be ruled out.

The aim of the present study was to describe the distribution of sarcoptic mange by means of a large-scale retrospective serosurvey and to try to determine the factors affecting the distribution of this disease in Spain. As well, a prospective survey in which rabbits were inspected for mange lesions was carried out on the island of Mallorca in order to better understand the epidemiology of this disease.

\section{Materials and methods}

\subsection{Study area and sampling}

Spain includes a variety of habitats and climates, which on the mainland can be simplified into five different bioregions according to the Wildlife Diseases Surveillance Scheme (Spanish Ministry of Environment). In our particular case, we consider the Balearic Islands to be a sixth bioregion due to the isolation of its rabbit populations from those of peninsular Spain. We did not obtain any samples from bioregion 1, where rabbits are scarce. Table 1 summarises the most relevant characteristics of each bioregion.

Serums samples dating from 1993 to 2010 from a total of 966 wild rabbits from 53 areas in 17 Spanish provinces or islands were analyzed in the retrospective serosurvey (Table 2 and Fig. 1). The majority of rabbits were shot by hunters, although some were sampled during translocations. Fourteen samples were obtained from Dragonera, a 290 ha island that is part of the Balearic archipelago. It is

Table 1

Characteristics of the bioregions of Spain included in this study.

\begin{tabular}{|c|c|c|}
\hline Bioregion & Climate & Environment \\
\hline 2.- Northern plateau & $\begin{array}{l}\text { Continental Mediterranean climate. Dry, hot summers; } \\
\text { dry, cold winters. Mean annual precipitation: } 808 \mathrm{~mm} \text {; } \\
\text { mean annual temperature: } 10.5^{\circ} \mathrm{C} \text {. }\end{array}$ & $\begin{array}{l}\text { Open landscape with cereal cultivation and pine and/or } \\
\text { oak woodland; bordered to the north by mountains. }\end{array}$ \\
\hline 3.- South central & $\begin{array}{l}\text { Continental Thermo-Mediterranean climate. Mean } \\
\text { annual precipitation: } 605 \mathrm{~mm} \text {; mean annual } \\
\text { temperature: } 14.5^{\circ} \mathrm{C} \text {. }\end{array}$ & $\begin{array}{l}\text { Pastures and croplands with patches of vegetation, } \\
\text { sometimes forming savannah-like structures. Low } \\
\text { altitude mountains with scrubland. }\end{array}$ \\
\hline 4.- Interior mountains & $\begin{array}{l}\text { Severe Continental Mediterranean climate. Mean } \\
\text { annual precipitation: } 568 \mathrm{~mm} \text {; mean annual } \\
\text { temperature: } 11.3^{\circ} \mathrm{C} \text {. }\end{array}$ & $\begin{array}{l}\text { Limestone upland and high-plateau habitats with } \\
\text { cereal crops, pastures and pine and/or oak woodlands. }\end{array}$ \\
\hline 5.- South and east coast & $\begin{array}{l}\text { Coastal Thermo-Mediterranean climate; arid in the } \\
\text { centre. Mean annual precipitation: } 720 \mathrm{~mm} \text {; mean } \\
\text { annual temperature: } 15.7^{\circ} \mathrm{C} \text {. }\end{array}$ & $\begin{array}{l}\text { Only a few well preserved wildlife habitats } \\
\text { (mountains). }\end{array}$ \\
\hline 6.- Balearic Islands & $\begin{array}{l}\text { Coastal Thermo-Mediterranean climate. Mean annual } \\
\text { precipitation: } 400-500 \mathrm{~mm} \text {; mean annual } \\
\text { temperature: } 18^{\circ} \mathrm{C} \text {. }\end{array}$ & $\begin{array}{l}\text { Mixture of croplands (mainly devoted to wheat), olive } \\
\text { groves and vineyards. }\end{array}$ \\
\hline
\end{tabular}

Adapted from the Wildlife Diseases Surveillance Scheme (Spanish Ministry of Environment). 
Table 2

Seroprevalence to Sarcoptes scabiei in wild rabbits in the areas, provinces and bioregions included in the study.

\begin{tabular}{|c|c|c|c|c|c|c|}
\hline Province/island & Code & Mange reported & Areas positive/surveyed & Rabbits positive/total & Seroprevalence (\%) & 95\% C.I. \\
\hline Huesca & $\mathrm{HU}$ & & $1 / 1$ & $5 / 30$ & 8.3 & $6.5-9.3$ \\
\hline Lérida & $\mathrm{L}$ & & $3 / 5$ & $4 / 56$ & 7.1 & $2.5-17.6$ \\
\hline Zaragoza & $\mathrm{Z}$ & & $1 / 2$ & $8 / 60$ & 13.3 & $6.3-24.8$ \\
\hline Bioregion 2 & & & $5 / 8$ & $17 / 146$ & 11.6 & $7.1-18.1$ \\
\hline Ciudad Real & CR & & $5 / 6$ & $29 / 97$ & 29.9 & $21.6-39.6$ \\
\hline Córdoba & $\mathrm{CO}$ & & $3 / 3$ & $2 / 64$ & 3.1 & $0.6-10.7$ \\
\hline Jaén & $\mathrm{J}$ & & $1 / 1$ & $2 / 6$ & 33.3 & $6.3-72.8$ \\
\hline Sevilla & SE & & $1 / 1$ & $3 / 17$ & 17.6 & $5.0-41.6$ \\
\hline Toledo & TO & & $4 / 5$ & $10 / 91$ & 11.0 & $5.8-19.1$ \\
\hline Bioregion 3 & & & $14 / 16$ & $46 / 275$ & 16.7 & $12.7-21.6$ \\
\hline Albacete & $\mathrm{AB}$ & & $3 / 5$ & $11 / 100$ & 11.0 & $5.9-18.9$ \\
\hline Madrid & $\mathrm{M}$ & & $2 / 3$ & $6 / 29$ & 20.7 & $9.4-39.5$ \\
\hline Bioregion 4 & & & $5 / 8$ & $17 / 129$ & 13.2 & $8.1-20.1$ \\
\hline Cádiz & $\mathrm{CA}$ & & $1 / 1$ & $4 / 30$ & 13.3 & $4.7-29.8$ \\
\hline Huelva & $\mathrm{H}$ & & $1 / 1$ & $8 / 30$ & 26.7 & $13.1-44.9$ \\
\hline Tarragona & $\mathrm{T}$ & Yes & $3 / 6$ & $3 / 63$ & 4.8 & $1.3-13.2$ \\
\hline Valencia & V & Yes & $3 / 7$ & $6 / 172$ & 3.5 & $1.5-7.4$ \\
\hline Bioregion 5 & & & $8 / 15$ & $21 / 295$ & 7.1 & $4.6-10.6$ \\
\hline Dragonera & DR & & $1 / 1$ & $5 / 14$ & 35.7 & $15.3-62.9$ \\
\hline Ibiza & IB & & $0 / 1$ & $0 / 25$ & 0.0 & $0.0-11.8$ \\
\hline Mallorca & MA & Yes & $3 / 4$ & $20 / 82$ & 24.4 & $16.1-34.7$ \\
\hline Bioregion 6 & & & $4 / 6$ & $25 / 121$ & 20.7 & $14.2-28.6$ \\
\hline Total & & & $32 / 53(60.4 \%)$ & $126 / 966$ & 13.0 & $11.0-15.3$ \\
\hline
\end{tabular}

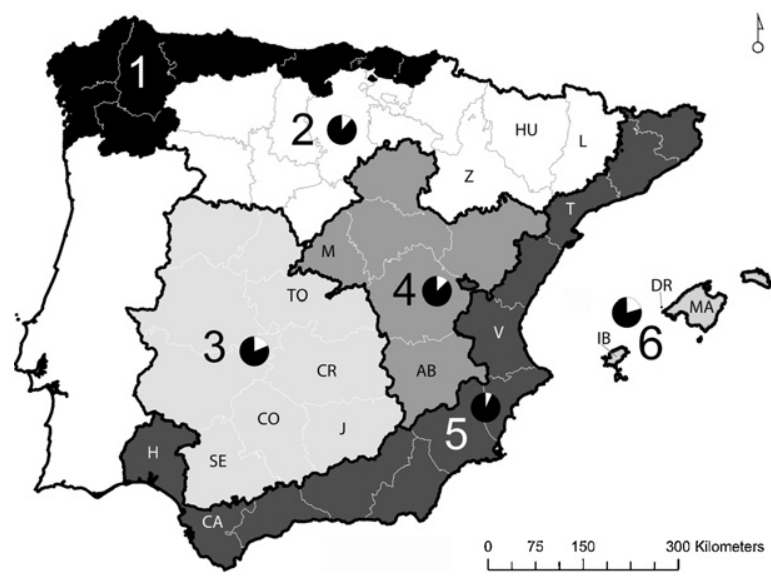

Fig. 1. Map of Spain showing the bioregions and provinces and islands included in the study (see Table 2 for codes). Diagrams indicate seroprevalence in each bioregion (proportion of seropositives is in white).

currently a protected site and, despite the lack of relevant scientific information, rabbits have not been released there since at least the 1970s. Sex and age was determined following Sáenz de Buruaga et al. (2001). Data on sex was available for 711 rabbits and data on age was available for 842 rabbits. Localities were categorized depending on whether rabbits had ever been released during restocking campaigns to reinforce populations; information was gathered via interviews with hunters and/or game managers. The areas studied were roughly divided into three categories depending on the relative abundance of rabbits (low, medium and high). Since only one locality fitted in the low abundance category, this area was eventually included in the medium abundance category. Samples were obtained by a variety of researchers performing a number of different types of study, and thus the relative abundance of rabbits was determined by means of different techniques (hunting bags, pellet counts, night surveys).

On Mallorca, a prospective survey was also carried out. Eighty-two wild rabbits were aged, sexed and inspected for lesions by the same vet (JM; see Millán, 2010 for details). Serum was obtained from all the rabbits. Serological results were also included in the national serosurvey.

\subsection{Serological analysis}

All sera were tested to detect specific antibodies to $S$. scabiei using a recently developed ELISA test based on the presence of the protein $S s \lambda 20 \Delta B 3$, an immunodominant antigen of the mite (Casais et al., 2007). This ELISA has been used successfully for the immunodiagnosis of S. scabiei in other of wild animals (Casais et al., 2007; Oleaga et al., 2008a,b; Falconi et al., 2010), although the version we used was adapted to test for the specific humoral response to $S$. scabiei in rabbits using as secondary antibody peroxidaseconjugated to Protein A, which specifically recognises rabbit IgG. Results were expressed as a percentage of the relative optical density (\% relative $\mathrm{OD}_{450 \mathrm{~nm}}$ ), which was calculated according to the following formula:

$\mathrm{OD}=\frac{\mathrm{OD}_{\text {sample_serum }}-\mathrm{OD}_{\text {negative_serum }}}{\mathrm{OD}_{\text {positive_serum }}-\mathrm{OD}_{\text {negative_serum }}} \times 100$

where blood serum taken at week 11 and the pre-immune serum from a experimentally infested rabbit were used in all the plates as positive and negative controls, respectively. The cut-off level of the ELISA test, calculated as the mean 
of the \% relative $\mathrm{OD}_{450 \mathrm{~nm}}$ from 24 scabies-free wild rabbits plus three times the standard deviation (Bornstein and Wallgren, 1997; Hollanders et al., 1997), was estimated as $6.7 \%$.

Sera from 49 rabbits from Mallorca were also analyzed for the presence of antibodies against myxoma virus and RHD virus by an indirect ELISA (OIE, 2010).

\subsection{Statistical analysis}

Differences in seroprevalence and the prevalence of lesions relative to sex, age and seroprevalence to myxomatosis and RHD were studied using $\chi^{2}$ test or Fisher's Exact Test with PASW Statistics 17.0. Tree-based modelling (De'ath and Fabricius, 2000) was conducted to examine the factors explaining the probability of contact with the mite (i.e., being seropositive) using R 2.12.0 (R Development Core Team, 2010). The predictor variables tested were annual rainfall, mean, maximum and minimum temperatures, relative rabbit abundance and restocking.

\section{Results}

The overall seroprevalence in rabbits was $13.0 \%$. Seropositive rabbits were found in $60.4 \%$ of the surveyed areas and in all studied provinces and islands except the island of Ibiza (Fig. 1 and Table 2). Seroprevalence was higher in bioregion 6 than in bioregions $5\left(\chi^{2}=16.0\right.$, $p<0.001, n=416)$ and $2\left(\chi^{2}=4.0, p<0.05, n=267\right)$. Seroprevalence in bioregion 5 was also lower than in bioregions $3\left(\chi^{2}=12.7, p<0.001, n=570\right)$ and $4\left(\chi^{2}=4.0, p<0.05\right.$, $n=424)$.

Seropositive rabbits were found in all the years studied (Fig. 2), with results ranging from $1.8 \%$ in 2007 to $33 \%$ in 2003. Nevertheless, since rabbits were sampled in different areas in different years, we were unable to compare years. Only in one area (into Albacete province) were rabbits sampled twice and there $9 / 20$ rabbits were found to be seropositive in 2003 and 0/22 in 2007 (Fisher's $p<0.001$ ).

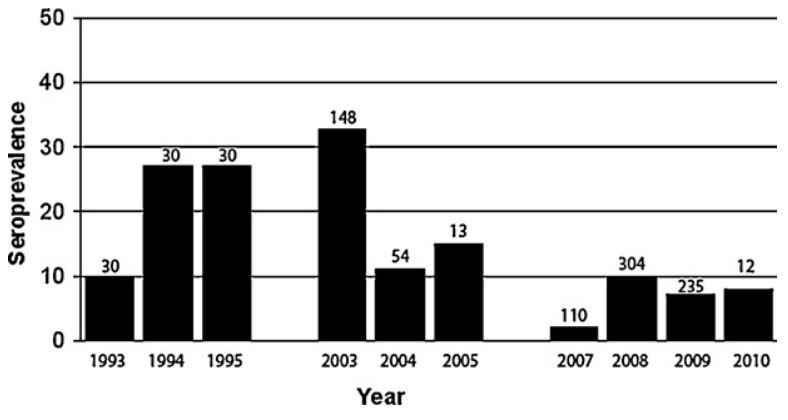

Fig. 2. Seroprevalence per year of antibodies against Sarcoptes scabiei in wild rabbits in Spain. Sample size is indicated in the top of the bar.

Seroprevalence in the oldest samples analyzed was $10 \%$ in 1993 and $26.7 \%$ in 1994 and 1995 . Interestingly, 36\% of rabbits sampled from the Dragonera were seropositive.

Seroprevalence was higher in males (11.0\%) than in females, although statistical differences were only marginally significant $\left(6.9 \% ; \chi^{2}=3.8, p=0.052, n=711\right)$. Taking into account only rabbits surveyed in positive areas, these differences were even more evident (18.8\% vs. $11.8 \%$; $\left.\chi^{2}=3.9, p<0.05, n=420\right)$. No age-related differences were found, either in the set of all areas $\left(\chi^{2}=2.0, p>0.05, n=842\right)$ or only positive areas $\left(\chi^{2}=1.9, p>0.05, n=532\right)$.

The tree model (Fig. 3) indicated that rabbit abundance was the most important factor affecting contact with the parasite: seroprevalence was higher in areas of medium rabbit abundance (33\%) than in areas with high abundances (10\%). In areas with mid-range abundances, restocking was the second most important factor explaining seroprevalence, which was higher when no restocking was performed. In areas without restocking, seroprevalence was higher in areas of greater rainfall, as it was also in areas of high rabbit abundance.

In Mallorca, the prevalence of lesions was 5.6\% and seroprevalence was $24.4 \%$. These differences were significant $\left(\chi^{2}=9.1, p<0.001\right)$. Antibodies were found in four out of five mangy rabbits. No sex or age-related differences were

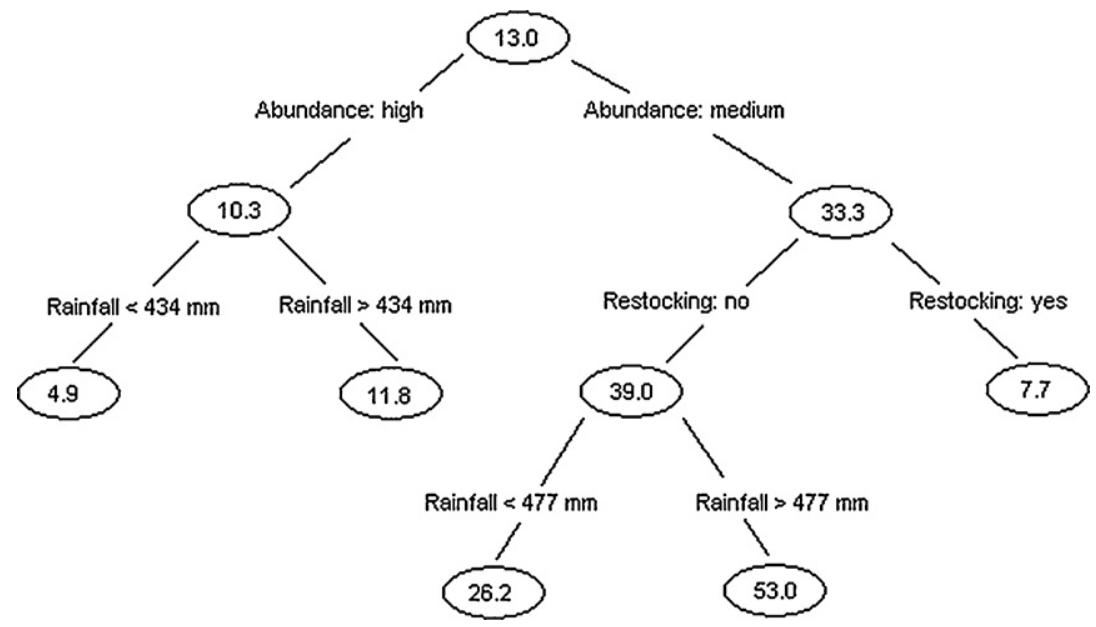

Fig. 3. Tree resulting from the analysis of factors affecting seroprevalence to Sarcoptes scabiei in wild rabbits in Spain. Values into the circles are seroprevalences. See text for details of the statistical analysis. 
detected in prevalences. The presence of antibodies against mange and against myxomatosis were not independent (Fisher's $p<0.05$ ). No relationship was found between seroprevalence of mange and RHD.

\section{Discussion}

The results indicate that wild rabbits in Spain often come into contact with $S$. scabiei. The actual rate of contact with the mite is probably higher than the $13 \%$ observed since it has been shown that the antibody levels in the blood of experimentally infected - but subsequently healed - domestic rabbits fall dramatically just four months postinfestation (Arlian et al., 1994). Consequently, some wild rabbits with titres just below the threshold may have been exposed in the past.

It could be argued that these antibodies are a consequence of exposure to a strain of $S$. scabiei from other species (e.g., red fox) that may not have caused disease in the seropositive rabbits. However, two arguments refute this hypothesis. First, it is well-known that scabies mites are largely host specific (Arlian, 1989). Second, the screening of a S. scabiei var. hominis amplified library Yv4 in previous studies (Fischer et al., 2003) enabled an immunodominant antigen to be identified in infected animals (Casais et al., 2007), which was used to develop an ELISA subsequently employed with success in the immunodiagnosis of S. scabiei in various species of wild animals (Casais et al., 2007; Oleaga et al., 2008a,b; Falconi et al., 2010). We adapted this ELISA to detect the specific humoral response to $S$. scabiei in rabbits. Using a panel of sera taken from experimental infestations in domestic rabbits, we showed that it is possible to detect $100 \%$ of infested rabbits from week 6 post-infestation onwards, that is, a couple of weeks before the first lesions become obvious (unpublished data). The specificity of the test was $100 \%$ because all pre-immune sera resulted negative. Moreover, previous work has shown that serum from tick-infested animals does not cross-react with the selected antigen, Ss $\lambda 20 \Delta$ B3. Therefore, we believe that the antibodies detected with the ELISA used in this study were developed after contact with the strain of $S$. scabies that causes mange in wild rabbits rather than after contact with a strain from other wild or domestic species. However, the identity of this strain or variety is still to be determined by means of molecular analyses.

Both Millán (2010) and Navarro-González et al. (2010) have speculated that the recently observed sarcoptic mange outbreaks were subsequent to the release of rabbits in the affected areas. The results of the present serosurvey show that mange has been present in Spanish rabbit populations since at least 1993, the date of the oldest available samples. Moreover, scabies can even be associated with rabbits from before this date because seropositive rabbits were found on the protected island of Dragonera, where it seems that no rabbits have been released since at least the 1970s. In addition, the seroprevalence of rabbits from Mallorca was much higher than the proportion of diseased animals, which indicates that rabbits often survive infection (although this could also be due to the fact that the ELISA test is able to detect infected rabbits before they develop visible lesions). All this evidence supports the theory that sarcoptic mange is enzootic in European wild rabbits in the Iberian Peninsula and the Balearic Islands, contrary to the conclusions drawn by Navarro-González et al. (2010). Nevertheless, the fact that mange is enzootic in wild rabbits does not necessarily imply that rabbit translocations are not responsible for the introduction of mange into certain naïve populations. For example, mange could have been introduced into the Balearic Islands in the past, since rabbits had no means of arriving on these islands without human help. As mentioned above, rabbit translocations are becoming increasingly frequent in the Iberian Peninsula for both hunting and conservation purposes. Thus, sanitary controls should be performed in order to avoid the introduction of parasites such as S. scabiei during rabbit translocations.

If mange is enzootic in wild rabbits, why was it not reported before the recent communication by Millán (2010)? First of all, the possibility exists that the mutagenesis of an established - but previously less pathogenic strain of S. scabiei has taken place (Pence et al., 1983). Second, external factors such as extreme weather conditions or reduced food availability may result in increased susceptibility to the parasite in rabbit populations (Pence et al., 1983; Gortazar et al., 1998; Arlian, 1989; Pérez et al., 1997; Pence and Ueckermann, 2002). In fact, we have observed that rainfall is one of the factors that is related with the presence of antibodies against $S$. scabiei (see below). Third, the effect of concomitant diseases may exacerbate what would otherwise be an asymptomatic mange infection (Balestrieri et al., 2006). For example, wild rabbit populations are known to suffer from periodical outbreaks of myxomatosis and RHD with mortality rates varying between years and places (Calvete et al., 2002; Cotilla et al., 2010) that may be related with mange outbreaks. In fact, we found an association between the presence of antibodies to S. scabiei and to myxoma virus. Lastly, a sociological consideration - namely the current increasing number of wildlife veterinarians in Spain - may have resulted in better surveillance and disease recognition compared than in the twentieth century, when such professionals were almost non-existent in Spain.

Male rabbits were found to have higher seroprevalence than females. Pérez et al. (1997) detected a higher prevalence of lesions in female Iberian ibex, although no hypothesis was given to explain these differences. If female rabbits are also more prone to suffer and eventually die from mange, this may explain the observed higher seroprevalence in males. On the other hand, males seem to have higher contacts with other rabbits rather than females because they occupied larger home ranges and are in charge of the territory defence (Cowan, 1987). This said, we found no sex-related differences regarding the presence of lesions in Mallorca. Nevertheless, the immunological response to $S$. scabiei is complex and difficult to interpret. For example, according to Sarasa et al. (2010), previous exposure to the mite may induce a sex-biased modulation of the IgG Sarcoptes-specific response in the Iberian ibex whereby previously exposed males have lower IgG responses than naïve males. Further studies are needed if we are to fully understand the immunological response of wild rabbits to $S$. scabiei. 
A higher seroprevalence was observed in areas with medium rabbit abundances. Mange is believed to be a density-dependent disease because it is transmitted directly (Pence and Ueckermann, 2002; but see Gortazar et al., 1998). The inverse relationship between the prevalence of immunized rabbits and host abundance observed in this study may be secondary to some degree of disease-related mortality in areas with higher population abundance due to social stress and the scarcity of trophic resources in overpopulated areas. Rainfall was also found to be an important factor explaining the probability of a rabbit coming into contact with the parasite. It is well known that survival away from the host is highly dependent on ambient temperature and relative humidity $(\mathrm{RH})$; greater $\mathrm{RH}$ reduces mite desiccation and favours survival (Arlian, 1989). Mange outbreaks in rabbits may therefore be related with periods of higher precipitation.

In the only area where rabbits were sampled twice, seroprevalence was higher in 2003 than in 2007. This can be a consequence of diverse factors, such as differences in rainfall or rabbit abundance, or to a variation in the proportion of susceptible individuals into the population. However, with the type of study carried out, we cannot conclude that seroprevalence is lower in recent times than it was earlier.

In conclusion, we have demonstrated that mange was present in wild rabbits earlier than once believed and that scabies should be considered as enzootic in European wild rabbit populations in Iberia. Further studies aimed at better understanding the strain of S. scabiei infecting wild rabbits, as well as the immunological behaviour of wild rabbits after exposure and re-exposure to the mite and the demographic effects of this parasite on rabbit populations should thus be conducted in the future.

\section{Acknowledgements}

We wish to thank B. Seguí and A. Barceló (Consell de Mallorca, Balearic Islands Government). E. Serrano kindly assisted us with statistical analyses. Laboratorios Larrasa performed the serological tests for myxomatosis and RHD. This work was partially funded by the Conselleria de Medi Ambient, Govern de les Illes Balears (contract no. 5893/2008), the Junta de Castilla-la Mancha (POII09-00992557, PEII09-0097-4363, and LIFE 07/NAT/E/000742) and Project CGL-2009-11665 (all co-founded with EU FEDER). Research involving adaptation of the ELISA to the serodiagnosis of sarcoptic mange in rabbits and serological tests was supported by grant RTA09-00114-00-00 from the Spanish Instituto Nacional de Investigación y Tecnología Agraria y Alimentaria (INIA). J. Millán holds a Ramón y Cajal contract and M. Delibes-Mateos a Juan de la Cierva contract, both awarded by the Ministerio de Ciencia e Innovación and the European Social Fund.

\section{References}

Angulo, E., Villafuerte, R., 2003. Modelling hunting strategies for the conservation of wild rabbit populations. Biol. Conserv. 115, 291-301.

Arlian, L.G., 1989. Biology, hunt relations and epidemiology of Sarcopres scabiei. Ann. Rev. Entomol. 34, 139-161.
Arlian, L.G., Morgan, M.S., Vyszenski-Moher, D.L., Stemmer, B.L., 1994 Sarcoptes scabiei: the circulating antibody response and induced immunity to scabies. Exp. Parasitol. 78, 37-50.

Balestrieri, A., Remonti, L., Ferrari, N., Ferrari, A., Lo Valvo, T., Robetto S., Orusa, R., 2006. Sarcoptic mange in wild carnivores and its cooccurrence with parasitic helminths in the western Italian Alps. Eur. J. Wildlife Res. 52, 196-201.

Bornstein, S., Wallgren, P., 1997. Serodiagnosis of sarcoptic mange in pigs. Vet. Rec. 141, 8-12.

Calvete, C., Estrada, R., Villafuerte, R., Lucientes, J., Osácar, J.J., 2002. Epidemiology of viral hemorrhagic disease (VHD) and myxomatosis in the wild rabbit (Oryctolagus cuniculus) in the mid-Ebro Valley, Spain Vet. Rec. 150, 776-782.

Casais, R., Prieto, M., Balseiro, A., Solano, P., Parra, F., Martín Alonso, J.M., 2007. Identification and heterologous expression of a Sarcoptes scabiei cDNA encoding a structural antigen with immunodiagnostic potential. Vet. Res. 38, 435-450.

Cotilla, I., Delibes-Mateos, M., Ramírez, E., Castro, F., Cooke, B.D., Villafuerte, R., 2010. Establishing a serological surveillance protocol for rabbit hemorrhagic disease by combining mathematical models and field data: implication for rabbit conservation. Eur. J. Widlife Res. 56, 725-733.

Cowan, D.P., 1987. Aspects of the social organisation of the European wild rabbit (Oryctolagus cuniculus). Ethology 75, 197-210.

De'ath, G., Fabricius, K.F., 2000. Classification and regression trees: a powerful yet simple technique for ecological data analysis. Ecology 81 3178-3192.

Delibes, M., Hiraldo, F., 1981. The rabbit as prey in the Iberian Mediterranean ecosystem. In: Myers, K., MacInnes, C.D. (Eds.), Proceedings of the I World Lagomorph Conference. University of Guelph, Guelph, Ontario, pp. 614-622.

Delibes-Mateos, M., Delibes, M., Ferreras, P., Villafuerte, R., 2008a. The key role of European rabbits in the western Mediterranean Basin hotspot. Conserv. Biol. 22, 1106-1117.

Delibes-Mateos, M., Ramírez, E., Ferreras, P., Villafuerte, R., 2008b. Translocations as a risk for the conservation of European wild rabbit Oryctolagus cuniculus lineages. Oryx 42, 259-264.

Delibes-Mateos, M., Farfán, M.A., Olivero, J., Vargas, J.M., 2010. Land-use changes as a critical factor for long-term wild rabbit conservation in the Iberian Peninsula. Environ. Conserv. 37, 1-8.

Falconi, C., Oleaga, A., López-Olvera, J., Casais, R., Prieto, M., Gortázar, C., 2010. Prevalence of antibodies against selected agents shared between Cantabrian chamois (Rupicapra rupicapra parva) and domestic goats. Eur. J. Wild Res. 56, 319-325.

Fernández-Morán, J., Gómez, S., Ballesteros, F., Quirós, P., Benito, J.L., Feliú, C., Nieto, J.M., 1997. Epizootiology of sarcoptic mange in a population of cantabrian chamois (Rupicapra pyrenaica parva) in northwestern Spain. Vet. Parasitol. 15, 163-171.

Fischer, K., Holt, D.C., Harumal, P., Curried, B.J., Walton, S.F., Kemp, D.J., 2003. Generation and characterization of cDNA clones from Sarcoptes scabiei var. hominis for an expressed sequence tag library: identification of homologues of house dust mite allergens. Am. J. Trop. Med. Hyg. 68, 61-64.

Gálvez-Bravo, L., Belliure, J., Rebollo, S., 2009. European rabbits as ecosystem engineers: Warrens increase lizard density and diversity. Biodivers. Conserv. 18, 869-885.

González-Candela, M., León-Vizcaíno, L., Cubero-Pablo, M.J., 2004. Population effects of sarcoptic mange in Barbary sheep (Ammotragus lervia) from Sierra Espuña Regional Park, Spain. J. Wildlife Dis. 40, 456-465.

Gortazar, C., Villafuerte, R., Blanco, J.C., Fernández-de-Luco, D., 1998. Enzootic sarcoptic mange in red foxes in Spain. Z. Jagdwiss. 44, 251-256.

Hollanders, W., Vercruysse, J., Raes, S., Bornstein, S., 1997. Evaluation of an enzyme-linked immunosorbent assay (ELISA) for the serological diagnosis of sarcoptic mange in swine. Vet. Parasitol. 69, 117-123.

León-Vizcaíno, L., Ruíz de Ybáñez, M.R., Cubero, M.J., Ortíz, J.M., Espinosa, J., Pérez, L., Simón, M.A., Alonso, F., 1999. Sarcoptic mange in Spanish ibex from Spain. J. Wildlife Dis. 35, 647-659.

Millán, J., 2010. First description of sarcoptic mange in wild European rabbit (Oryctolagus cuniculus). Eur. J. Wildlife Res. 56, 455-457.

Mörner, T., 1992. Sarcoptic mange in Swedish wildlife. Rev. Sci. Tech. Off. Int. Epizoot. 11, 1115-1121.

Navarro-González, N., Serrano, E., Casas-Díaz, E., Velarde, R., Rossi, L., Marco, I., Lavín, S., 2010. Game restocking and the introduction of sarcoptic mange in wild rabbit in Northeastern Spain. Anim. Conserv. $13,586-591$

OIE, 2010. Manual of diagnostic tests and vaccines for terrestrial animals 2010. http://www.oie.int/eng/normes/mmanual/a_summry.htm (accessed 11.29.2010) 
Oleaga, A., Balseiro, A., Gortazar, C., 2008a. Sarcoptic mange in two roe deer (Capreolus capreolus) from Northern Spain. Eur. J. Wildlife Res. $54,134-137$.

Oleaga, A., Casais, R., González-Quirós, P., Prieto, M., Gortázar, C., 2008b. Sarcoptic mange in red deer from Spain: improved surveillance or disease emergence? Vet. Parasitol. 154, 103-113.

Pence, D.B., Ueckermann, E., 2002. Sarcoptic mange in wildlife. Rev. Sci. Tech. Off. Int. Epizoot. 21, 385-398.

Pence, D.B., Winberg, L.A., Pence, B.C., Sprowls, R., 1983. The epizootiology and pathology of sarcoptic mange in coyotes, Canis latrans, from south Texas. J. Parasitol. 69, 1100-1115.

Pérez, J.M., Ruiz-Martínez, I., Granados, J.E., Soriguer, R.C., Fandos, P., 1997. The dynamics of sarcoptic mange in the ibex population of Sierra Nevada (Southern Spain). Influence of climatic factors. J. Wildlife Res. $2,86-89$.
R Development Core Team, 2. 12. 0, 2010. A Language and Environment for Statistical Computing. R Foundation for Statistical Computing, Vienna, Austria (accessed 22.10.10) http://www.R-project.org.

Sáenz de Buruaga, M., Lucio, A., Purroy, F.J., 2001. Reconocimiento de Sexo y Edad en Especies Cinegéticas. Edilesa, León, Spain.

Sarasa, M., Rambozzi, L., Rossi, L., Meneguz, P.G., Serrano, E., Granados, J.E., González, F.J., Fandos, P., Soriguer, R.C., González, G., Joachim, J., Pérez, J.M., 2010. Sarcoptes scabiei: Specific immune response to sarcoptic mange in the Iberian ibex Capra pyrenaica depends on previous exposure and sex. Exp. Parasitol. 124, 265-271.

Skerratt, L.F., Martin, R.W., Handasyde, K.A., 1998. Sarcoptic mange in wombats. Aust. Vet. J. 76, 408-410.

Villafuerte, R., Calvete, C., Blanco, J.C., Lucientes, J., 1995. Incidence of viral hemorrhagic disease in wild rabbit populations in Spain. Mammalia 59, 651-659. 